\title{
A Simple Method to Control The Excitation Angle for Switched Reluctance Motor
}

\author{
Slamet Riyadi ${ }^{1}$ \\ ${ }^{1}$ Department of Electrical Engineering, Soegijapranata Catholic University, Indonesia
}

\begin{tabular}{l} 
Article Info \\
\hline Article history: \\
Received Oct 21, 2020 \\
Revised May 20, 2021 \\
Accepted Jun 14, 2021 \\
\hline
\end{tabular}

\section{Keywords:}

Switched reluctance motor

Excitation angle

Electric drive

Input capture

Control strategy

\begin{abstract}
A switched reluctance motor (SRM) has been an alternative solution for electric drives because of its benefit features. The use of such a motor in electric vehicles (EVs) or hybrid electric vehicles (HEVs) requires a control strategy that is capable to develop high torque. SRMs are commonly available in the market with rotor position detectors embedded inside. Problems will appear when such detectors are not symmetrically installed because most of SRM control strategies are commonly based on them. Inaccurate pulses will be generated by the control circuit which finally takes effect on phase current commutation or the beginning of the excitation which is not on proper angle. The use of such detectors is just capable to give information of rotor position in common angles. Improvement for such problems can be done by generating pulses related to the rotor position in smooth angles. In this paper, a control strategy to produce excitation signals with proper angles for SRM stator winding is proposed. By using input capture facility that is commonly available in embedded system, excitation angles can be controlled precisely because a large number of pulses can be produced by the system. Accuracy level of this strategy is determined by TIMER period of embedded system and speed of SRM. To verify the analysis, laboratory experiments were done. They show that the proposed control strategy is capable to rotate the motor with better performance.
\end{abstract}

Copyright () 2019 Institute of Advanced Engineering and Science. All rights reserved.

\section{Corresponding Author:}

Slamet Riyadi,

Department of Electrical Engineering,

Soegijapranata Catholic University,

Pawiyatan Luhur IV-1 Semarang, Indonesia

Email: riyadi@unika.ac.id ; sriyadi7167@gmail.com

\section{INTRODUCTION}

Switched reluctance motor (SRM) has been a strong candidate for electric drive due to its simple structure, ruggedness, low cost, fault tolerance capability and reliability. Applications for hybrid electric vehicles (HEVs) or electric vehicles (EVs) require high torque developing capability [1], [2]. SRM also has problems related to its large torque ripple. To improve the performance of SRM in HEV or EV, many efforts have been developed to produce torque with higher magnitude and lower ripple. Modification of machine design and improvements of control strategy can be taken to reduce torque ripple of SRM. The second method in reducing torque ripple is more preferable due to costs and is faster to implement, such control strategies include current profiling, torque sharing function and direct instantaneous torque control. Frequency and time domain based current profiling by utilizing finite element analysis or current tracking control that is based on pre-computed current profile can be used to mitigate ripple torque in SRMs [3], [4]. In torque sharing function, reference torque for individual phases are generated due to total reference torque, the reference torque for individual phases are translated into current command signals according to rotor position. Finally, these current references are then compared with the actual phase currents by current controller [5]-[7]. To control the SRM torque directly with lower ripple contents, space vectors can be used. The vectors of stator flux linkage is kept at a constant amplitude while the torque is controlled by acceleration or deceleration of stator flux linkage vectors by choosing the appropriate voltage space vector [8]-[10]. 
Besides torque ripple, magnitude of developed torque in SRM is also a key to obtain better performance of SRM drives. An SRM can produce positive or negative torque, it depends on how the phase winding current is excited. To produce the positive torque, the phase winding must be excited during the phase inductance increases, it occurs while the rotor is traveling from unaligned to aligned position. To have an accurate command, information of rotor position is required. Sensored and sensorless methods for SRMs have been developed. To increase reliability and reduce costs, sensorless based control strategies are commonly used. One of the sensorless methods is flux linkage method which requires a lot of experimental data so large space of memory is required by such a method. Simplified flux linkage method is developed to overcome the previous method [11] or using numerical method to calculate the rotor position based on flux linkage-positionphase current characteristics [12]. The rotor angle can also be estimated by using real time adaptive filter based on the supply voltage and phase current [13]. Position sensorless detections can also use the slope of phase inductance of SRM stator winding [14], or vector of the inductance slope [15], [16]. All the sensorless methods have complexity in deriving the rotor position estimation. They also require initial start-up process [17], [18].

Sensor based control methods are easier to be implemented in SRM drive, the use of rotary encoder is able to control the excitation angle [19]. Due to the limitations of the rotary encoder, nonintrusive reflective or non-contact sensors are also implemented [20], [21]. Most of SRMs are commonly available in the market with rotor position detectors embedded inside. Hall-effect based detectors can only give information on common angles so the excitation process will be inaccurate. Such sensors have been implemented in many applications due to simplicity in control circuit but some modifications must be made to get better performance.

Highly precision in placements of such rotor position sensors inside the motor are quite difficult so some problems will arise. To produce higher torque in SRM drives, it requires proper angles for excitation, so the concept of how to generate rotor position information related to smoother angles must be designed. In this paper, a simple method to control the excitation angles for SRM stator windings is proposed. This strategy is capable to excite the phase windings on proper angles. By using input capture facility which is available in digital signal controller, accurate angles are determined for phase stator windings with respect to the reference position. The proposed control strategy is able to overcome the problems related to the inaccuracy of the placements and the limitation of hall effect sensors.

\section{RESEARCH METHOD}

\subsection{Basics of Switched Reluctance Motor}

An SRM has simple structure, it consists of phase windings on its stator and a salient rotor without permanent magnets or windings. This motor operates due to reluctance phenomenon. When the stator and rotor are in aligned position $\left(\theta_{\mathrm{al}}\right)$, the stator winding has maximum inductance and minimum reluctance. Meanwhile, minimum inductance is achieved when they are in unaligned position $\left(\theta_{\mathrm{u}}\right)$.

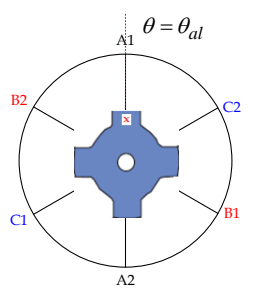

(a)

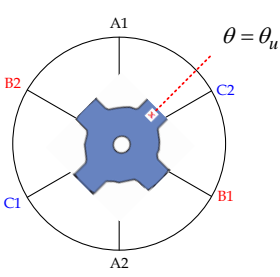

Figure 1. Phase-A of a switched reluctance motor under (a) aligned position (b) unaligned position

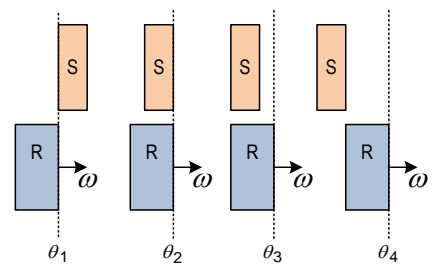

(a)

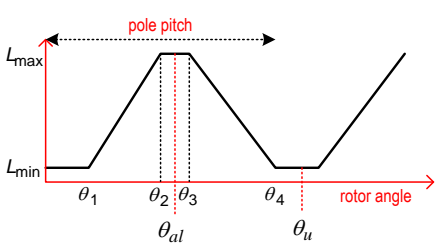

(b)

Figure 2. Rotor position influence on the phase inductance (a) rotor movement (b) phase inductance curve

The equivalent circuit of SRM is shown in Fig.3, by neglecting effects caused by saturation, fringing flux, leakage flux and mutual inductance, voltage equation can be derived as the following [22] 


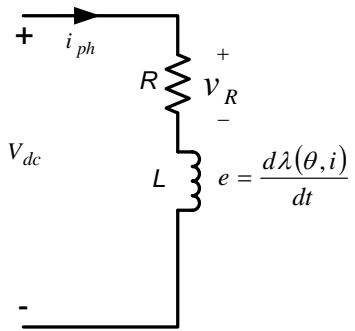

Figure 3. Equivalent circuit of Switched Reluctance Motor

$$
V_{d c}=R \cdot i_{p h}+e\left(\theta, i_{p h}\right)=. i_{p h}+\frac{d \lambda\left(\theta, i_{p h}\right)}{d t}
$$

where $V_{d c}, R, i_{p h}, e, \theta$ and $\lambda$ are DC source voltage, phase resistance, phase current, back EMF, rotor position and linkage flux. Based on (1), the torque $(T)$ developed by the SRM is expressed as

$$
T=\frac{1}{2} i_{p h}^{2} \frac{d L(\theta)}{d \theta}
$$

Direction of the torque stated in (2) is determined by the slope of the phase inductance $(L)$ as depicted in Fig.4. When the stator is excited in region during positive slope of the phase inductance (from unaligned to aligned position), positive torque will be produced, meanwhile excitation during negative slope of the phase inductance (from aligned to unaligned position) will result in negative torque. The difference between the negative and positive torque will be the net torque that will rotate the rotor.

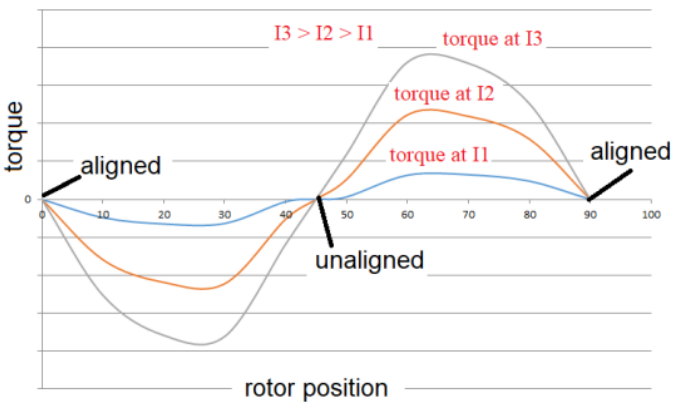

Figure 4. Generation of the positive and negative torque on SRM

To develop the optimum torque of the SRM, the stator winding current must be turned off as soon as possible when the aligned position is passed. This can be done by using voltage with negative polarity as available in asymmetric converter and C-dump Converter [23]. In this paper, asymmetric converter is used to drive SRM as depicted in Fig.5, voltage equation under magnetizing mode can be stated as

$$
V_{d c}=R \cdot i_{p h}+L \frac{d}{d t} i_{p h}+e
$$

By neglecting the phase resistance, then the slope of the phase current can be obtained as

$$
\frac{d}{d t} i_{p h}=\frac{V_{d c}-e}{L}
$$

and under demagnetizing mode, voltage and current equations are expressed as

$$
\begin{aligned}
-V_{d c} & =R . i_{p h}+L \frac{d}{d t} i_{p h}+e \\
\frac{d}{d t} i_{p h} & =-\frac{\left(V_{d c}+e\right)}{L}
\end{aligned}
$$




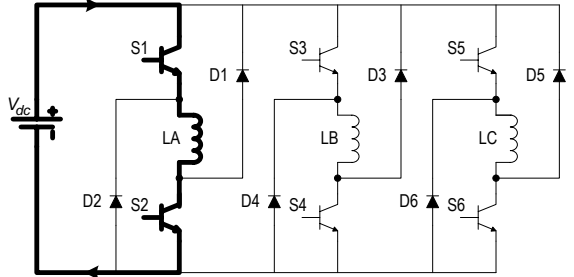

(a)

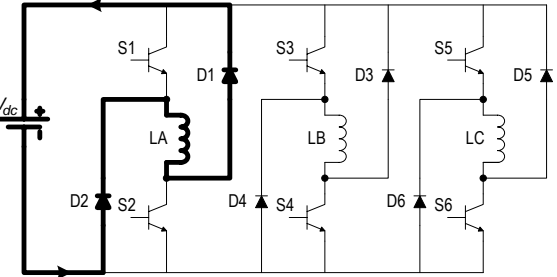

(b)

Figure 5. Asymmetric Converter for SRM (a) during magnetizing (b) during demagnetizing

For the nature of the inductive circuit, the excitation voltage is commonly applied before the phase inductance starts to increase. If the instant time for the phase winding excitation is too early, the phase current will have greater value because the phase inductance is still small so it results in poor efficiency. SRMs are commonly available with the rotor position detectors embedded inside. For three phase SRMs, they have three detectors that are displaced 60 degree denoted as $\mathrm{H}_{1}, \mathrm{H}_{2}$ and $\mathrm{H}_{3}$ so they can generate information of rotor positions represented by 001, 010, 011, 100, 101 and 110. For 6/4 SRM, the commutation will occur on every 30 mechanical degree (Fig.6), the switching configuration based on such detectors depicted as $S_{A}, S_{B}$ and $S_{C}$. In order to have the capability to shift the commutation angles in smooth and precise values, the control strategy must be modified.

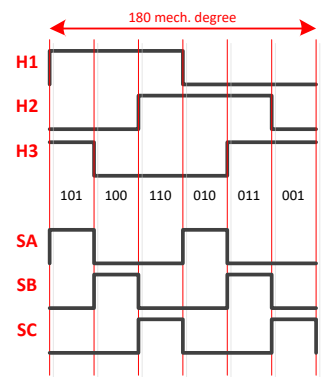

Figure 6. Information signals produced by rotor position detectors for stator windings excitation

\subsection{Control of The Excitation Angle for Stator Winding}

Input capture (IC) is a feature that is commonly available on an embedded system. If a pin of the embedded system which is functioned as an input capture pin receives a signal, then the value of TIMER register will be captured on every transition of this input signal (every rising edge or falling edge). An interrupt can also be generated in such event. The proposed control strategy only uses one signal from hall effect sensor $\left(\mathrm{H}_{1}\right)$ as the signal for input capture pin. For SRM with 4 poles rotor and 6 poles stator, such a signal is shown in Fig.7. In this case, let us consider the value $X_{0}$ and $X_{1}$ are instant values of the TIMER register which are captured in the previous input capture event and in the recent input capture event, and NP is the number of signals captured between the both events, NP is also the difference between $\mathrm{X}_{1}$ and $\mathrm{X}_{0}$. Two adjacent input capture events may occur before (Fig.8a) or is separated by TIMER overflow (Fig.8b), and then NP can be calculated by including the TIMER period (PR). For events as depicted in Fig.8a, n equals to 0, meanwhile as depicted in Fig.8a, n equals to 1.

$$
N P=X_{1}+n P R-X_{0}
$$

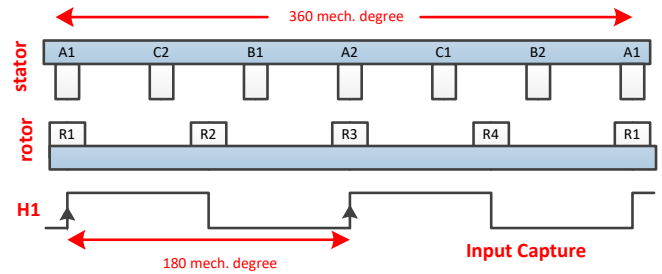

Figure 7. Input capture signal generated by one of the rotor position detector 


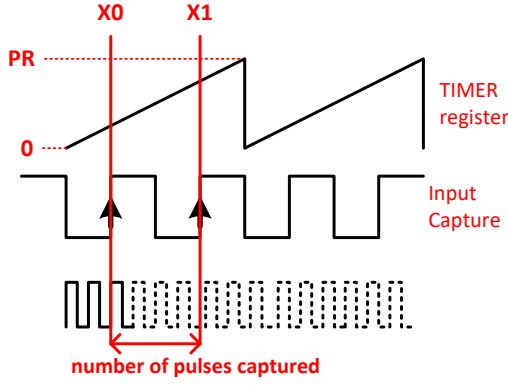

(a)

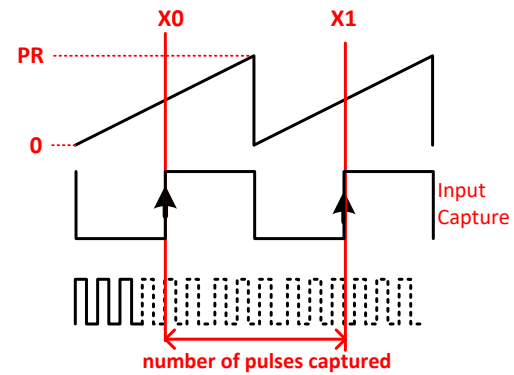

(b)

Figure 8.(a) two adjacent input capture events occur before TIMER is overflow (b) two adjacent input capture events are separated by TIMER overflow

Then a carrier signal can be made due to the instant values of the TIMER register (TMR) and $\mathrm{X}_{0}$ as the following

$$
\begin{aligned}
& \text { Carr }=T M R-X_{o} \text { if } T M R \geq X_{o} \\
& \text { Carr }=T M R+P R-X_{o} \text { if } T M R \leq X_{o}
\end{aligned}
$$

The use of one signal from rotor position detector $\left(\mathrm{H}_{1}\right)$ results in every capture will occur for 180 mechanical degree. Such a condition requires two pairs of excitation signals that must be generated between two adjacent capture events as depicted in Fig.9. Equations of these excitation signals are stated below

$$
\begin{aligned}
& X_{\text {on-ph(1) }}=X_{\text {on-ref }}+\frac{k \cdot N P}{6} \\
& X_{\text {on-ph(2) }}=X_{\text {on-ref }}+\frac{(k+3) \cdot N P}{6} \\
& X_{\text {off-ph(1) }}=X_{\text {off -ref }}+\frac{k \cdot N P}{6} \\
& X_{o f f-p h(2)}=X_{\text {off-ref }}+\frac{(k+3) \cdot N P}{6}
\end{aligned}
$$

where $\mathrm{ph}=\mathrm{A}, \mathrm{B}, \mathrm{C}$ and $\mathrm{k}=0,1,2 . \mathrm{X}_{\mathrm{on}-\mathrm{ph}(1)}$ is the number of pulses when the phase stator winding start to be excited for the first time after event of input capture, $X_{\mathrm{on}-\mathrm{ph}(2)}$ is the number of pulses when the phase stator winding start to be excited for the second time and $\mathrm{X}_{\text {on-ref }}$ represents the any number of pulses after unaligned position $\left(\theta_{\mathrm{u}}\right)$. Meanwhile $\mathrm{X}_{\mathrm{off}-\mathrm{ph}(1)}$ and $\mathrm{X}_{\mathrm{off}-\mathrm{ph}(2)}$ represents the number of pulses when the phase stator winding start to be turned off for the first and second time, while $\mathrm{X}_{\text {off-ref }}$ represents the any number of pulses before aligned position $\left(\theta_{\mathrm{al}}\right)$. $\mathrm{X}_{\mathrm{on}-\mathrm{ref}}$ and $\mathrm{X}_{\mathrm{off}-\mathrm{ref}}$ are empirically determined.

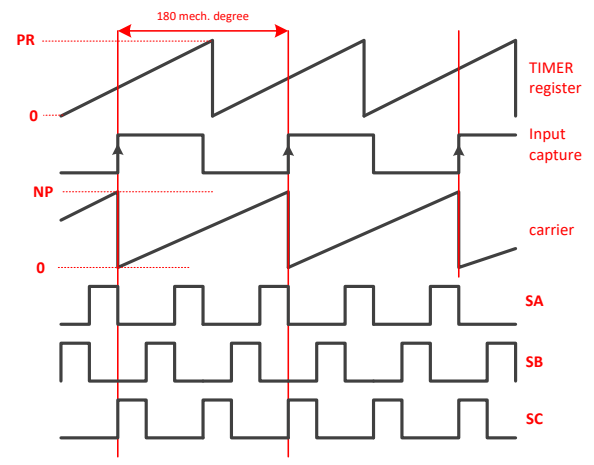

Figure 9. Phase winding excitation pulses $\left(\mathrm{S}_{\mathrm{A}}, \mathrm{S}_{\mathrm{B}}, \mathrm{S}_{\mathrm{C}}\right)$ generated based on the value of TIMER register captured

For $\mathrm{X}_{\mathrm{off}}$ is greater than $\mathrm{X}_{\mathrm{on}}$, the excitation signal for a stator winding can be expressed as

if $X_{o n-p h}\left\langle\right.$ carrier then $Y_{1}=1$ else $Y_{1}=0$

if $\left.X_{\text {off-ph }}\right\rangle$ carrier then $Y_{2}=1$ else $Y_{2}=0$ 


$$
S=Y_{1} \cap Y_{2}
$$

Under condition where $\mathrm{X}_{\mathrm{on}}$ is greater than $\mathrm{X}_{\mathrm{off}}$, the excitation signal is formed by

$$
S=Y_{1} \cup Y_{2}
$$

where $Y_{1}, Y_{2}$ are the pulse width modulation waveforms formed by the intersection of $X_{o n}, X_{o f f}$ and the carrier. $S_{A}, S_{B}$ and $S_{C}$ are the excitation signals for the phase stator windings meanwhile $S$ is general form of $S_{A}, S_{B}$ and $\mathrm{S}_{\mathrm{C}}$.

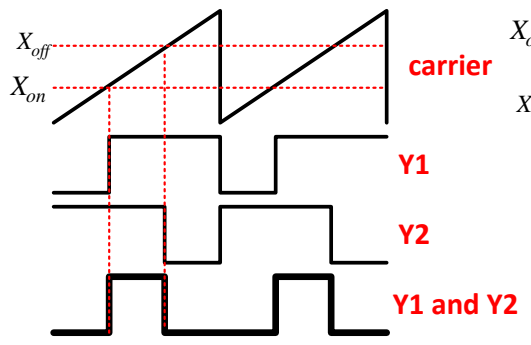

(a)

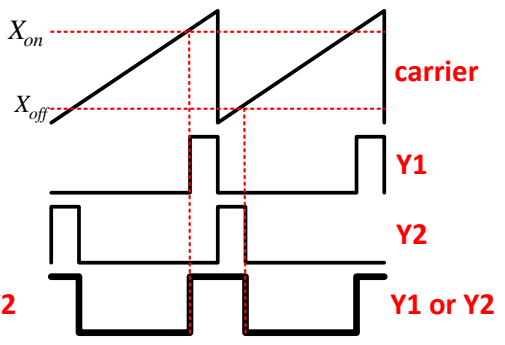

(b)

Figure 10. Control the width of a stator windings excitation signal (a) where $\mathrm{X}_{\text {off }}$ is greater than $\mathrm{X}_{\text {on }}$ (b) where $X_{o n}$ is greater than $X_{o f f}$

The effectiveness of the above method depends on the width of $\mathrm{H}_{1}$ signal and $\mathrm{PR}$. The proposed strategy will be valid if the width $\mathrm{H}_{1}$ is smaller than $2 \mathrm{PR}$ because only one event of TIMER overflow is considered. This strategy can be improved by modification of input capture subroutine.

\section{RESULTS AND DISCUSSION}

Hardware implementation of the proposed control strategy is designed by using a Digital Signal Controller, a 16-bit microcontroller dsPIC30F is chosen as a core of the control circuit. Calculation of the number of pulses captured between two adjacent input capture events is done in the input capture INTERRUPT subroutine as depicted in Fig.11 and the main algorithm is shown in Fig.12. In the subroutine, number of captured pulses (NP) is calculated due to (7). These values will be used in the algorithm to generate carrier signal for PWM patterns. Then, the excitation angles for phase-A, phase-B and phase- $\mathrm{C}$ are calculated based on Eq.(10)-(15).

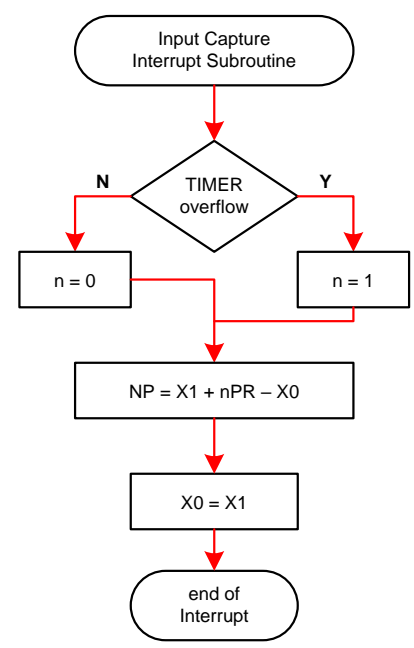

Figure 11. Flowchart to calculate the number of the pulses captured

To verify the analysis, laboratory experiments were done based on the block diagram and the prototype depicted in Fig.13 and Fig.14. The experiments were conducted under two control strategies, first the SRM was operated by using three hall effect sensors embedded in the SRM as the input signals of the control circuit, meanwhile the second control strategy uses one of the hall effect sensor output as the input 
signal for input capture pin. Fig.15 shows the waveforms of one hall effect sensor output and excitation signals for the three stator windings. The problems appear due to the difficulty in installation of the three hall effect sensors symmetrically. These results in the excitation signals for the three stator windings are not identical. Such condition will cause the excitation signal width is different, finally the current with different peak value for one phase will appear (Fig.16) and then it leads to higher vibration. Inaccuracy of the sensor placement can also results in the beginning or the end of the excitation is too early or too late that can lead to operation with poor performance.
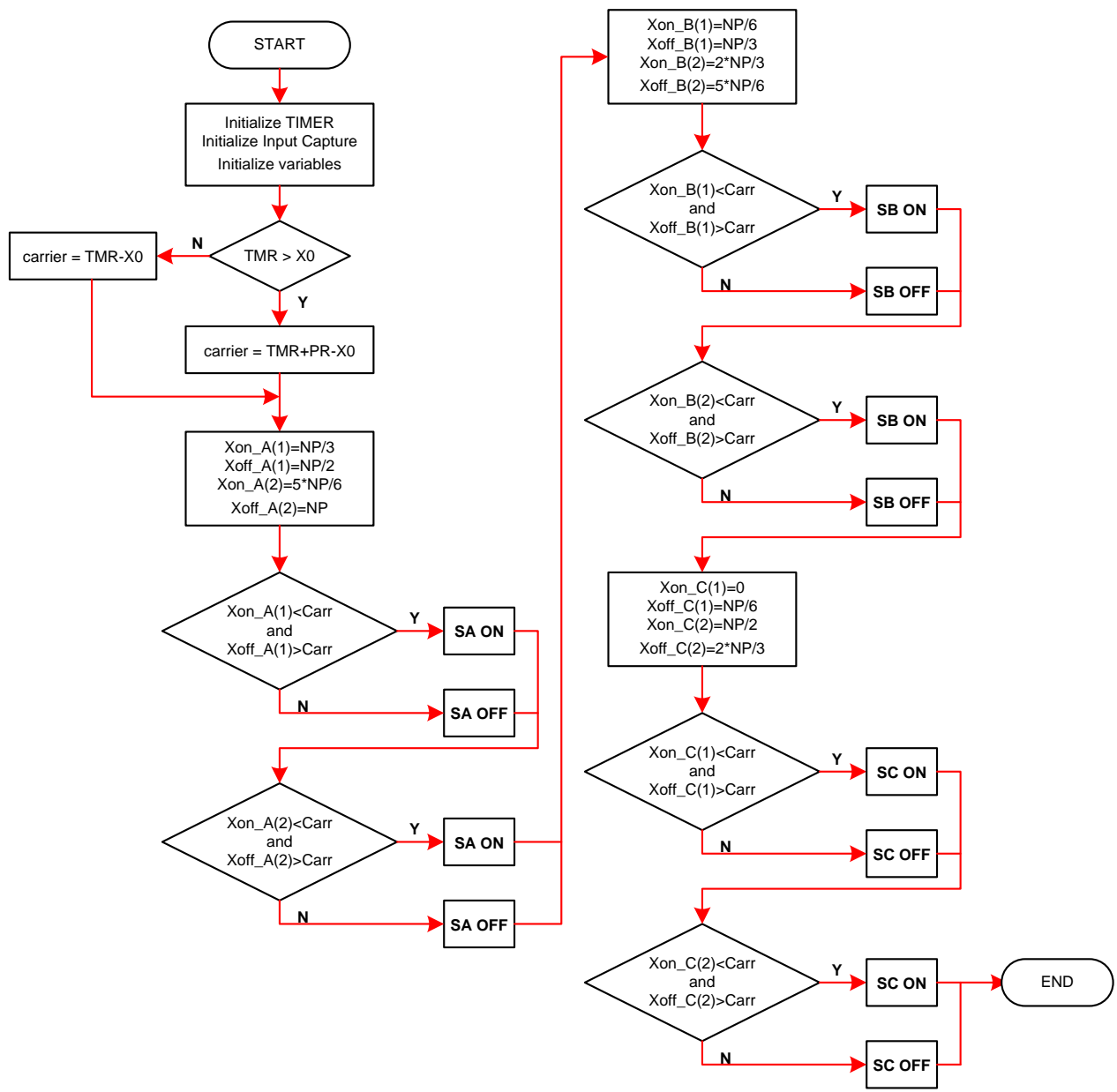

Figure 12. Flowchart to generate the control signals for three phase SRM Asymmetric Converter

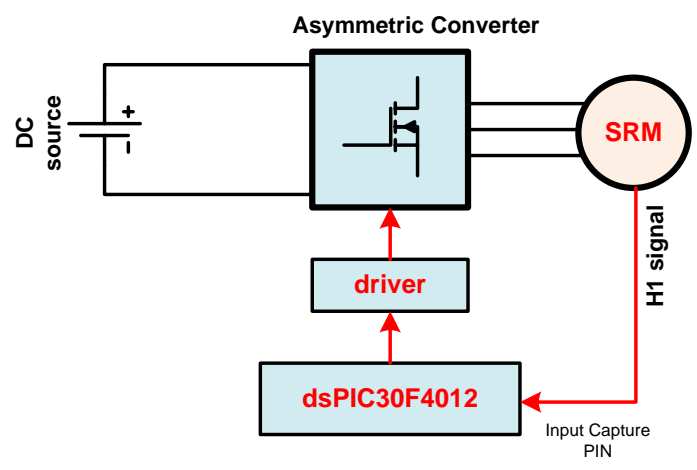

Figure 13. Scheme of the proposed system 


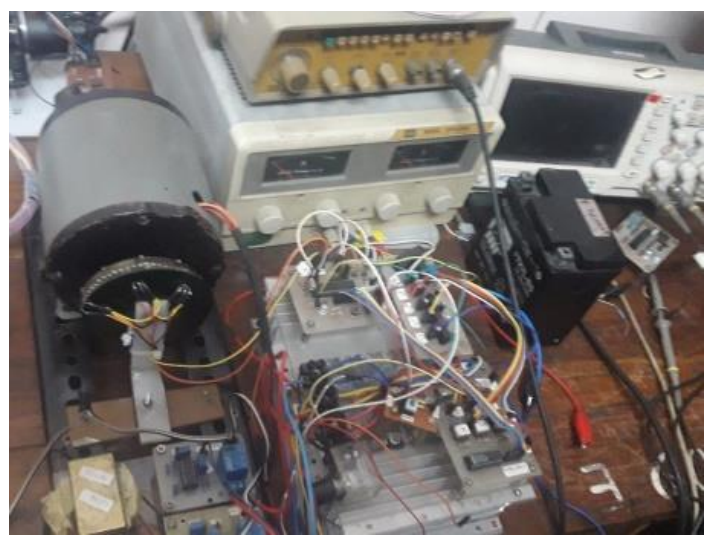

Figure 14. Hardware of the proposed system

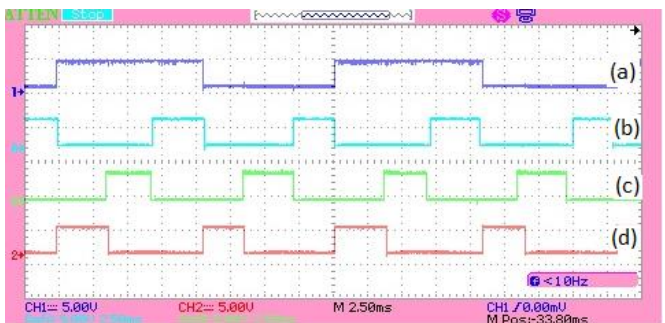

Figure 15. Experimental results using Hall effect detector (a) Hall effect-A signal (b-d) excitation signals for phase windings

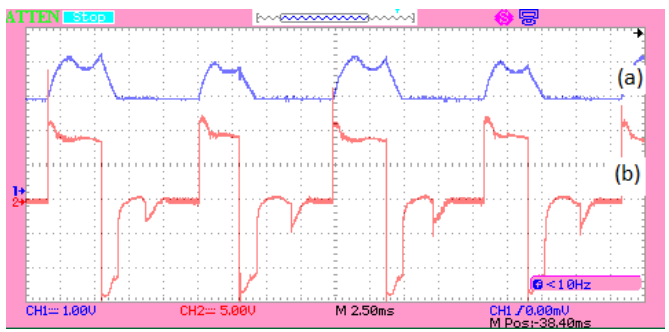

Figure 16. Experimental results using Hall effect detector (a) phase current (b) phase winding voltage

To improve the above shortcoming, a control strategy using input capture facility is implemented. The excitation signals for the windings of the SRM can be made identical. The instant time for turning on and turning off can also be controlled. The waveforms of the excitation signals are depicted in Fig.17. Excitation signals generated for the three phases are also identical. The phase currents flowing in the stator winding are nearly uniform (Fig.18) then finally it develops better performance. Comparison of the phase currents under two control strategies is presented in Fig.19. Under the same operating parameter, the period of the current waveform under the proposed strategy is smaller, it means that the SRM rotates at higher speed. The lower phase currents are also produced by the proposed control strategy.

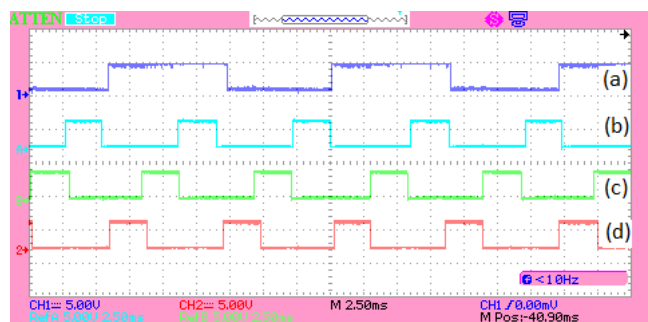

Figure 17. Experimental results with the proposed control strategy (a) input capture signal (b-d) signals for phase windings excitation 


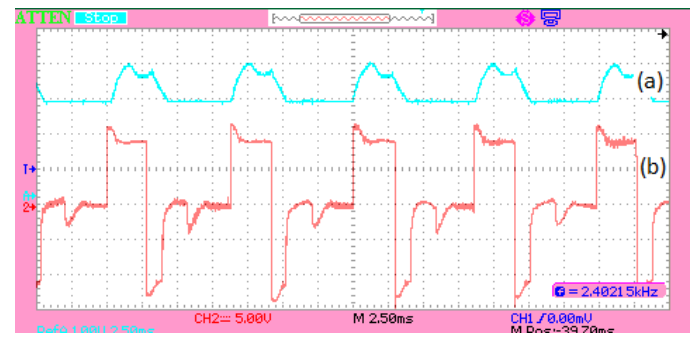

Figure 18. Experimental results with the proposed control strategy (a) phase current (b) phase winding voltage

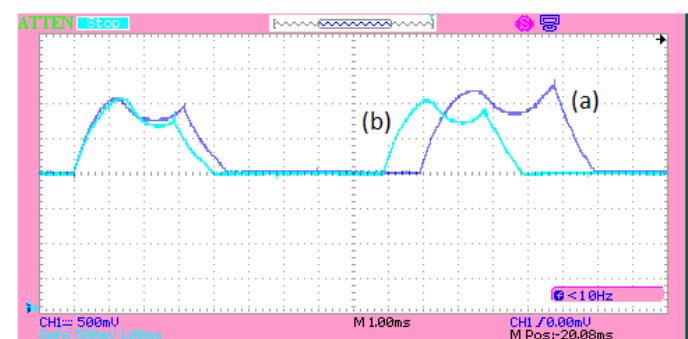

Figure 19. Comparison of phase currents between SRM using (a) hall effect sensor and (b) the proposed control strategy

The number of pulses (NP) in the proposed control strategy will vary according to the speed variation so the excitation angles which are produced through the determined number of pulses will always be adaptable. In design, the value of periods (PR) must be chosen due to the width of the input capture event. Minimum speed of SRM which can be covered by this strategy is limited by period of $\mathrm{H}_{1}$ signal so starting method is still required

\section{CONCLUSION}

The strategy to control the instant time to turn on and turn off the phase windings for a switched reluctance motor has been presented. By using one of the rotor position detectors as the signal for input capture pin, variation of the excitation angle can be made accurately. The number of pulses between two input capture events can be calculated as the basic to determine the instant time for turning on and off the stator windings currents. The experimental results show that the proposed control strategy is capable to produce identical phase currents and to operate the SRM under better performance.

\section{ACKNOWLEDGMENTS}

This work was supported by Directorate of Research and Community Service, Directorate General of Research Strengthening and Development, The Ministry of Research, Technology and Higher Education, Republic of Indonesia under the scheme of PTUPT 2019.

\section{REFERENCES}

[1] H. Cheng, Z. Wang, S. Yang, J. Huang and X. Ge, "An Integrated SRM Powertrain Topology for Plug-In Hybrid Electric Vehicles With Multiple Driving and Onboard Charging Capabilities", IEEE Transactions on Transportation Electrification, vol.6, no.2, pp.578-591, June 2020

[2] C. Gan, J. Wu, W. Kong, H. Li and Y. Hu, "A Review on Machine Topologies and Control Techniques for LowNoise Switched Reluctance Motors in Electric Vehicle Applications", IEEE Access, vol.9. pp. 31430 - 31443, May 2018

[3] J.Dexter, et al., "Comparison of Frequency and Time Domain Based Current Profiling Techniques for Acoustic Noise Reduction in Switched Reluctance Machine”, 201821 st International Conference on Electrical Machines and Systems (ICEMS)

[4] T. Kusumi, et al., "Simple Control Technique to Eliminate Source Current Ripple and Torque Ripple of Switched Reluctance Motors for Electric Vehicle Propulsion", IECON 2016 - 42nd Annual Conference of the IEEE Industrial Electronics Society 
[5] S. Kurian, et al., "Torque Ripple Minimization of SRM Using Torque Sharing Function And Hysteresis Current Controller", 2015 International Conference on Control, Communication \& Computing India (ICCC)

[6] Y. Wei, et al., "Torque Ripple Reduction in Switched Reluctance Motor Using a Novel Torque Sharing Function", 2016 IEEE/CSAA International Conference on Aircraft Utility Systems, Beijing, China

[7] H. A. Maksoud, "Torque Ripple Minimization of a Switched Reluctance Motor using a Torque Sharing Function based on the Overlap Control Technique", Journal of Engineering, Technology \& Applied Science Research, Vol. 10, No. 2, pp. 5371-5376, 2020

[8] Y. Han , et al., "Torque ripple reduction of four-phase SRM based on DTC method", 2018 IEEE 3rd Advanced Information Technology, Electronic and Automation Control Conference

[9] X. Ai-de, Z. Xianchao, H. Kunlun and C. Yuzhao, "Torque-ripple reduction of SRM using optimised voltage vector in DTC", IET Electrical Systems in Transportation, , vol. 8, no. 1, pp. 35-43, 2018

[10] N. Yan, X. Cao and Z. Deng, "Direct Torque Control for Switched Reluctance Motor to Obtain High Torque-Ampere Ratio", IEEE Transactions on Industrial Electronics, vol.66, no.7, 2019

[11] T. Wang, et al., "Sensorless Control of Switched Reluctance Motor Drive Using an Improved Simplified Flux Linkage Model Method", 2018 IEEE Applied Power Electronics Conference and Exposition (APEC), pp. 2992-2998

[12] F. Peng, et al., "Position Sensorless Control of Switched Reluctance Motor based on Numerical Method", 2016 IEEE Energy Conversion Congress and Exposition (ECCE), pp. 1-8

[13] C. Pavlitov, et al., "Rotor Position Estimation for a Sensorless Switched Reluctance Motor Drive with the Aid of Real Time Adaptive Filter", 2014-16th International Power Electronics and Motion Control Conference and Exposition, pp. 77-81,

[14] J. Cai and Z. Deng, "A Position Sensorless Control of Switched Reluctance Motors Based on Phase Inductance Slope", Journal of Power Electronics, 13(2), pp. 264-274, March 2013

[15] J. Cai and Z. Deng, "Sensorless Control of Switched Reluctance Motor Based on Phase Inductance Vectors", IEEE Trans. on Power Electronics, 27(7), pp. 3410-3423, July 2012

[16] N. Itteera et al., "Rotor Position Estimation of 8/6 SRM using Orthogonal Phase Inductance Vectors", 2013 Annual IEEE India Conference (INDICON), pp. 1-4

[17] L. He, et al., "A New Method to Detect The Initial Position for Sensorless SRM", 2011 International Conference on Electronics, Communications and Control (ICECC), pp. 2450-2453

[18] Z. Makni, et al., "Effective Starting Procedure for a Three-phase Switched Reluctance Motor", 2014 Ninth International Conference on Ecological Vehicles and Renewable Energies (EVER), pp. 1-7

[19] S. Riyadi, "Control Strategy for Switched Reluctance Motor with Rotary Encoder based Rotor Position Detection", Advances in Electrical and Electronic Engineering, 16(3), pp. 261-270, 2018

[20] C. Gong, et al., "'Direct position control for ultra-high speed switched reluctance machines based on non-contact optical sensors", 2017 IEEE International Electric Machines and Drives Conference (IEMDC), pp. 1-6

[21] C. Gong, S. Li, T. Habetler, J. Restrepo and B. Soderholm, "Direct Position Control for Ultrahigh-Speed SwitchedReluctance Machines Based on Low-Cost Nonintrusive Reflective Sensors", IEEE Trans. on Industry Applications, 55(1), pp. 480-489, Jan/Feb 2019

[22] S. Riyadi, "A Control Strategy for SRM Drive to Produce Higher Torque and Reduce Switching Losses", Journal of Electrical Systems, vol.14, no.4, 2018

[23] S. Riyadi, et al., "Energy Efficient C-Dump Converter with Simple Control Strategy for SRM Drive", 2019-9 th International Conference on Power and Energy Systems (ICPES 2019), Perth Australia

\section{BIOGRAPHY OF AUTHOR}

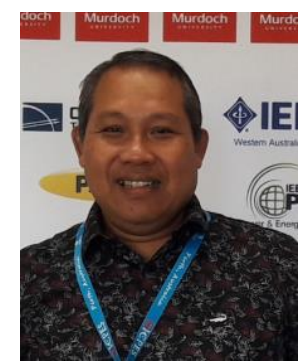

Slamet Riyadi was born in Semarang-Indonesia, in 1967. He received B.Eng. degree from Diponegoro University, Semarang in 1991. M.Eng. and PhD degrees from Bandung Institute of Technology, Bandung-Indonesia in 1997 and 2006. He also did PhD Partial Research in ENSEEIHT-INPT Toulouse, France in 2004. Currently, he is with the Department of Electrical Engineering, Soegijapranata Catholic University, Semarang - Indonesia as a lecturer and researcher. His current researches are focused on electric drives, PV-Grid systems, power factor correction techniques and active power filtering. Some of his researches were supported by, ASEM duo-France, The Ministry of Research and Technology - Indonesia, The Directorate General of Higher Education-Ministry of National Education - Indonesia, etc. 